shorter space of time, and frequently vesication resulted after an application of ten and sometimes of only five minutes. The effect of ethyl iodide was also found to be enhanced by the aid of external heat, and slight vesication could be produced with it after fifteen minutes of contact.

Incidentally, I may mention a fact of another kind, of some interest in regard to theories of counter-irritation, which was observed in the course of the above experiments. On one occasion I applied methyl iodide within an inch or so of a small area which was red from the application of ethyl iodide the day before. The part became only red, without effusion of serum, but free vesication resulted over the area which had been previously congester by the ethyl. The same was observed on another occasion with one of the iodine solutions; slight vesication only resulted at the part, but a full blister formed on a small neighbouring area which had been reddened some days before, but which otherwise would not have gone further. A similar phenomenon was once observed in a patient. A circular methyl blister about two inches in diameter was applied within an inch or two of an equal area which had been blistered by cantharides a few days before. The methyl was almost a failure, but a free flow of serum ensued at the seat of the fly blister, a fact which was noticed by the patient's mother, who called my attention to it.

From the preceding statements it will have been observed that the iodides of both ethyl and methyl are more powerful agents than the strong tincture of iodine already mentioned, aud which Dr. Churchill considered the best of all applications to the cervix uteri. ${ }^{6}$ As distinguished from most other agents which are applied to the cervix or the interior of the uterus, iodine is characterised by its tendency to produce a serous instead of a plastic exudation, but in this respect it is much surpassed by its methyl and ethyl compounds. These circumstances point to the two latter bodies as peculiarly applicable where such effects of iodine are deemed desirable; and I have found the application of methyliodide to the cervix have a remarkable effect in relieving pain in some forms of uterine disease. For milder effects and for application to the interior of the uterus the ethyl compound is an excellent agent. The effect of this body applied on a Playfair's probe to the fundus, and retained there one minute, is often remarkable. A few days afterwards the cervix has generally the soft feel and even the somewhat purplish tinge of the cervix of pregnancy. The cervical canal will frequently admit a sound which could not previously be passed; while pain is almost invariably relieved. But this is a subject requiring to be treated in some detail, and it must suffice merely to allude to it in the present communication. ${ }^{\top}$

Partick, Glasgow.

\section{FATAL CASE OF EQUINIA (FARCY).}

\section{BY T. W. HARROPP GARSTANG, M.R.C.S.}

ON July 22nd, 1885, I was called in to see a man, thirtysix years of age, nearly $6 \mathrm{ft}$. high, broad in proportion, and very powerfully built. He was a farmer, and the champion swordsman in his troop of yeomanry. He had always enjoyed exceptionally good health. His symptoms were very vague; there was really nothing more than a complaint that he did not feel quite up to the mark. His tongue was slightly furred, and it appeared as though he had only caught a little ordinary cold. A mixture was prescribed containing bicarbonate of potash, spirits of nitrous ether, and acetate of ammonia solution. On the 25th, the tongue being cleaner, but the patient still appearing depressed, a mixture was given containing tincture of perchloride of iron, tincture of nux vomica, and infusion of quassia. On the 28th this was replaced by bicarbonate of soda and infusion of calumba. On the 31st the patient appeared convalescent.

On Aug. 6th I was called in again. The patient had been out and about the farm; but had been listless and uneasy, and said he thought he must have got a little fresh cold.

6 Diseases of Women, fifth edition, pp. 217.18 and 307 .

Methyl iodide can only he obtained from some of the firms which deal in chemical reagents. What I have used lately was made in my own laboratory and I have never found it change so much with keeping from coming into contact with his own lanks, or troublesome itching will be the consequence.
His wife was more emphatic, and said that, whaterer the cause might be, she was convinced he was gradually losing flesh and strength. There was a slight but perceptible yellow tinge in the skin ; there was complaint of restlessness at night; some pain was felt at the pit of the stomach, an ill-defined pain in the left arm, and an uneasy sensation about the nose. Nitro-hydrochloric acid with calumba was given, and bromide of potassium at night. On the 10th the bromide was given with quinine. On the 11th there was a temperature of $102^{\circ}$, with increased pain over the stomach. I ordered the patient to bed, though quite at a loss for a diagnosis, wondering if it could be enteric fever. It was now mentioned for the first time that on July 14th he had been splashed on the right arm by a small quantity of discharge from the nostrils of a horse that had died of farcy but considering the rarity of cases of infection from this source, and the apparent absence of local or specific symptoms, I attached no weight to this incident, which hac occurred twenty-eight days previously. From this time, however, the patient began to complain of a persistent offensive tenacious discharge, which was felt to be in the nose, but was generally expelled irom the mouth by coughing. On the 12th violent vomiting supervened, with great pain over the stomach and a foul tongue. The case then had just the appearance of simple acute gastritis, and an effervescing mixture of citrate of potash was given with hydrocyanic acid. On the 14th the vomiting was relieved and the pain had now moved to the right side, where it was most intense. The temperature was $101^{\circ}$, the respiration 40 , and the pulse 100 . On palpation, the liver was felt to be very hard and uniformly enlarged. The restlessness at nights now increased, an il was very distressing. The temperature varied from $99^{\circ}$ to $10^{\circ} \mathrm{C}$ From and after the 15th chloral and bromide were freely used to produce sleep at nights. On the 16th I diagnosed abscess of the liver, and on the 17th asked Dr. Morgan (physician to the Royal Infirmary, Manchester), to see the patient with me, which he did on the 18th. We agreed as to the abscess of the liver, and there was now a spot of apparent phlebitis in the calf of the right leg. We considered the case one of pyæmia. A more minute questioning as to the early history now elicited the fact that the discharge, which had fallen on the arm, had been immediately wiped off with a "wisp of grass," the skin being perfectly sound to the best of the patient's belief. On the following day there had been an eruption of some "small red spots" at the site, to which the patient applied some "precipitate ointment" he happened to have by him, and they, after showing "white heads," had disappeared in a day or two and had been no more thought of. The earliest symptom of illness was now remembered to have been a feeling of oppression in the chest; his chest, he said, "was as sore as if it had been hit with a hammer." At this date (18th) the jaundice was more marked; the liver was swollen, hard, and intensely tender; and the nasal discharge above mentioned was very troublesome. The final conclusion was therefore reluctantly arrived at that the case was one of inoculation by the specific poison of farcy. Three grains of quinine was ordered to be taken three times a day. During the next few days, severe diarrhoea set in, and a very large quantity of gelatinous matter was passed, presumably pus from the hepatic abscess, as all the symptoms referred to the liver were concurrently relieved to a great extent. For two or three days the patient appeared to improve, but a number of other painful inflammatory spots ("farcy buds") developed in various situations. The worst was at the metacarpo-phalangeal joint of the middle finger of the left hand, which was expected for several days to burst spontaneously, but it eventually subsided, and at the same time a large patch of erysipelatous inflammation commenced at the root of the nose, and involved the whole of the upper part of the face. This was rapidly followed by delirium, then by coma, and death occurred on Aug. 31st. On the $22 \mathrm{nd}$ the dose of quinine had been increased to four grains and $\mathrm{a}$ half; and on the 26th to six grains, and five minim. of liquor arsen. hydrochlor. were added. On the 25th dose of one-twelfth of a grain of perchloride of mercury were given twice a day. The diet throughout was as abundent, nutritious, and stimulating as possible; and the appetite was good almost the whole time. There were, therefort, no unfarourable complications, and the patient had every chance. Nevertheless, the steady course of the disease nas never for a moment arrested.

The following appear to be the points of great interest in 
this case, and I gratefully acknowledge the kindness of Dr. Morgan, who drew my attention specially to many of them. He says: "In the first piace, it is reasonable to assume that the secretion from the nostrils of the horse, which (five days before constitutional symptoms supervened) was deposited on the inner surface of the patient's arm, made its way into the parts beneath, and inoculated the system. The man stated that there was no abrasion of the skin. Are we, then, to assume that the poison penetrated the intact epidermis, and afterwards affected the system (and some few such cases have been recorded), or was the skin excoriated br the wisp of grass used in wiping off the virus? In whatever manner the integument was entered, here doubtless the mischief commenced; yet it is a curious fact that no pain or discomfort was ever felt in this arm, the lymphatic glands in the limb remained altogether unaffected. When the constitutional symptoms did supervene, the most characteristic feature in the case was a sense of extreme discomfort experienced at the sternum, and a feeling (lasting nearly a fortnight) as though the chest were constricted in a vice." I have further to record this most interesting fact, that a farm labourer who underwent exactly the same risk of infection washed himself and escaped. In the above case there were never any rigors. The spleen was never positively felt to be enlarged. The nasal symptoms were present from the first. The abscess in the liver was apparently single. The disease might be roughly considered to have two stages; may we consider these as corresponding to the primary local and secondary constitutional stages of syphilis, for example? The site of infection never developed local symptoms. Death appeared to be immediately caused by extension to the brain of the inflammatory action commencing in the nose.

Knutsford.

\section{CASE OF AN OCTOGENARIAN UPON WHOM HERNIOTOMY WAS TWICE SUCCESS- FULLY PERFORMED.}

B T TOMAS F. CHAVASSE, SURGEON TO THE GENERAL HOSPITAL, BIRMINGHAM.

THE recuperative powers possessed by some advanced in years is exemplified by the following case.

Ann S-, aged eighty-two, a widow and washerwoman, was admitted into the General Hospital, Birmingham, on Aug. 17th, 1884, suffering from left strangulated femoral hernia. In the previous April she had been operated upon by my colleague, Mr. Pemberton, for a similar condition, and after a sojourn of eight weeks left the hospital wearing a truss. From that time up to the morning of the day of her second admission the woman had felt no inconvenience. The hernia then came down while straining at stool, and could not be returned by her own or her neighbours' efforts. At midday vomiting commenced, and at five o'clock in the afternoon she was brought to the hospital. Two hours later I found that the hernia was tense, irreducible, and devoid of impulse; the romiting was constant, but not frecal. Herniotomy was performed under chloroform, the skin incision being made a little internal to the old cicatrix. The sac was remarkably thin, and the intestine that presented itself was absolutely black. A very tight constriction existed at Gimbernat's ligament ; this was divided and at the same time I also nicked Poupart's ligament. Reduction could then be readily effected. Being very doubtful of the advisability of returning into the abdominal cavity a portion of gut so very black, I decided to place it just inside the ring and to insert a large drainagetube; this was done and the parts well washed with warm corrosive sublimate lotion (1 to 2000). The operation was performed on the bed in which the patient lay, and she was well wrapped up in blankets during its performance.

August 18th.-The patient vomited three times during the night, but the ejecta were not stercoraceous. The wound was dressed and the tube shortened. A grain of opium was administered occasionally, as a good deal of abdominal pain was complained of. The highest temperature and pulse records took place in the evening-viz., $1005^{\circ}$ and 98,-19th: Flatus was passed for the first time since the operation, and the drainage-tube was removed altogether.-21st: The bowels were opened of their own accord, and the external wound was nearly healed.Sept. 1st: Patient able to get up, wearing an oppositesided truss.

A year after the operation the woman presented herself for examination at my out-patient room, owing to the trus needing repairs. It was then found that the hernial protrusion was the size of a clenched fist, that it was readibly reducible, and gave rise to no inconvenience when kept back by a truss. The patient obtains her livelihood as a charwoman, and wishes that she was younger in order that she could do more work and get more money.

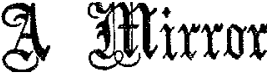

\section{HOSPITAL PRACTICE, BRITISH AND FOREIGN.}

Nulla autem est alia pro certo noscendi via, nisi quamplurimas et morborum et dissectionum historias, tum aliorum tum proprias collectas habere, et inter se comparare.-Morasani De Sed. et Caus. Morb., lib. iv. Procemium.

\section{LONDON HOSPITAL.}

CASES OF STRANGULATED HERNIA TREATED BY LIGATURE AND REMIOVAL OF SAC AND OMENTUM.

(Under the care of Mr. WAlter Rrvington.)

THE subject of the treatment of the sac and wound after the operation for strangulated hernia (especially umbilical) has attracted considerable attention of late. Last week, at the meeting of the Clinical Society, cases of umbilical hernia were brought forward in which, after operation, the hernial sac was removed and the margins of the opening brought together with catgut sutures. In the discussion which followed, the weight of opinion was in favour of this method of treatment, and the cases which follow show the advantages of it. In THE LANCET of Feb. 28th, 1885, page 381, we published a case in which the edges of the aperture were pared and afterwards brought together, but if peritoneal surfaces are accurately approximated, it is hardly necessary to do this. There can be no doubt that the removal of the sac in these cases, and complete closure of the opening, shuts off the peritoneal cavity and removes what is probably the greatest source of danger in these cases-the entrance of septic or other material from the wound. This alone is a strong argument for its adoption where practicable, as it is in the majority of cases, especially when the strangulation is of recent date.

CASE 1. Strangulated Right Femoral Hernia; Removal of Sac and Omentum; Recovery._- S. - , aged fortyfive, braidworker, was admitted from the receiving-room for a large femoral hernia on the right side. The tumour was the size of a large orange, and irreducible. The patient was in severe pain all over the abdomen, vomiting frequently, and in a state of collapse. The hernia had first appeared twenty years ago, directly after the birth of her first child. Since then the size of the tumour had varied rery much, sometimes being very large, and sometimes disappearing. The patient had always suffered more or less inconvenience from pain, which was often rery serere. At Christmas last she was in the hospital with symptoms of strangulated hernia, suffering great agony, witb constant vomiting and exhaustion. The hernia was reduced, and eventually she was sent out wearing a truss. On admission on the present occasion the rupture had been down for some days, and, taxis failing, an operation was performed on March 24th, 1885. After division of the superficial coverings, a thin-walled cyst which communicated with the sac was first opened, emitting serous fluid. The sac was then laid open, and Gimbernat's ligament notched through its neck. A knuckle of congested gut of a deep purple colour was reduced, and a considerable piece of omentum was removed. The sac was ligatured at the neck and cut away. The operation was performed under the carbolic spray, and the wound dressed with carbolic gauze. The bowels were opened the evening after the operation, and then were confined till the sixth day, after which they actec regularly. By April 1st the wound had nearly healed.

CiSE 2. Stranqulated Right Femoral Hernia; Remomal and Ligature of Sac; Recovery.-S. B-, aged fifty-seren, 